\title{
A Guideline Study for Designing Virtual Reality Games
}

Güven ÇATAK, Bahçeşehir University, Digital Game Design, Dr., guven.catak@comm.bau.edu.tr, (D) 0000-0002-4679-8973

Server Zafer MASALCI, Bahçeşehir University, Game Design, MA, szafermasalci@gmail.com, 0000-0002-5876-8210

Seray ŞENYER, Bahçeşehir University, Game Design, MA, seraysenyer@yandex.com, (DD 0000-0002$6243-2349$

\section{ABSTRACT}

Keywords : Virtual Reality, Game Design, Video Games, Virtual Worlds, Design Guideline

Virtual reality has great potential for immersive experiences that is not available in other mediums. Thus, it has a significant place in the entertainment and the game industry. However, creating a well-designed immersive experience can be extremely complicated due to the replacement of human perception from the real-world to an isolated virtual world. Understanding the essentials of virtual reality (VR) experiences and game design principles is necessary for designing an immersive VR game. Although there are many differences in design elements of $V R$ games according to the experience that is wanted to be given to the player, many games also have common elements. In the line of this view, a guideline is aimed to be framed for VR game designers in the current study. For this purpose, design pillars of VR experiences and game design principles were reviewed, and five VR games were analyzed.

Games are highly plastic mediums that can be adapted to any environment and technology. Many game types have a close relationship in terms of game elements and design. However, the implementation of game elements from other mediums to the VR medium is challenging. Therefore, game design principles should be wellcomprehended and implemented to the VR medium by considering the existed technology.

Virtual reality takes the player and put him in a new virtual world. In this world, everything should be designed to be easily perceivable by the player. Thus, the human perception was reviewed as one of the design pillars. Virtual reality also offers an interactive experience that allows the user to affect the world. Like in traditional video games, players can interact and navigate in the virtual world. Therefore, interaction and navigation were reviewed as two other design pillars. Based on the reviewed design pillars, five VR games were analyzed. Then, a VR game design guideline is proposed based on common game design elements in those games. 


\title{
Sanal Gerçeklik Oyunları Tasarımı İçin Bir Rehber Çalışması
}

$\ddot{O} Z$

\begin{abstract}
Sanal gerçeklik, diğer medya araçlarında olmayan tamamen kapsayıcı (içine alan) deneyimler sunabilmesi sebebiyle büyük bir potansiyele sahiptir. Bu nedenle eğlence ve oyun sektöründe önemli bir yer edinmektedir. Ancak, iyi tasarlanmış tamamen kapsayıcı deneyimler oluşturmak insan algı sistemlerinin gerçek dünyadan sanal dünyaya aktarımı nedeniyle oldukça zordur. Bu anlamda, sanal gerçeklik deneyimi tasarımının temellerini ve oyun tasarımı ilkelerini anlamak büyük önem arz etmektedir. Oyuncuya yaşatılmak istenilen deneyime uygun olarak sanal gerçeklik oyunlarının tasarımında farklı unsurlardan faydalanılsa da pek çok oyun, aynı zamanda, ortak unsurlar da paylaşmaktadır. Bu görüşten yola çıkılarak yapılan çalışma, sanal gerçeklik oyunu tasarımcilar için bir kılavuz oluşturmayı hedeflemektedir. Bu hedef doğrultusunda, sanal gerçeklik deneyimlerinin tasarm temelleri ve oyun tasarımı ilkeleri gözden geçirilerek, beş farklı sanal gerçeklik oyunu analiz edilmiştir.

Oyunlar, her ortama ve teknolojiye uyarlanabilen oldukça esnek yapılardır. Pek çok oyun türü, oyun tasarımı ve unsurları açısından yakın ilişki içerisindedir. Öte yandan, oyun unsurlarının başka bir ortamdan sanal gerçeklik ortamına aktarımı oldukça zorludur. Bu nedenle, oyun tasarm prensiplerinin iyi anlaşılması ve var olan teknoloji dikkate alınarak sanal gerçeklik ortamına aktarımı gerçekleştirilmelidir.

Sanal gerçeklik, oyuncuyu yeni bir sanal dünya içerisine alır. Bu dünyadaki her şeyin, oyuncunun kolay algılayabileceği şekilde tasarlanması gerekir. Yapılan çalışmada bu doğrultuda, tasarım temellerinden biri olarak insan algı sistemleri incelenmiştir. Geleneksel video oyunlarında olduğu gibi, oyuncular sanal dünyada etkileşime girebilmekte ve gezinebilmektedir. Bu nedenle, etkileşim ve gezinme diğer iki tasarım temeli olarak incelenmiş ve bu temeller doğrultusunda, beş sanal gerçeklik oyunu analiz edilmiştir. Ardindan, incelenen oyunlardaki ortak tasarım unsurlarından yola çıkılarak bir sanal gerçeklik oyun tasarımı kılavuzu sunulmuştur.
\end{abstract}

\section{Anahtar : Sanal Gerçeklik, Oyun Tasarım, Video Oyunları, Sanal Dünyalar, Tasarm Kelimeler Rehberi}

\section{INTRODUCTION}

Virtual Reality (VR) is one of the fastest developing communication mediums in the latest years. Expectations on worldwide statistics indicate that VR market volume will rise to 98.4 million sales by 2023, and will produce more than 16 billion US dollars by 2022 (Rogers, 2019; Statista, 2020). Although VR technology has the potential to be benefited from various fields, it is majorly used by the media, game, and entertainment industries for today. The main reason behind its value is the great potential of immersive experience that is only available in the VR but not in the other mediums. Virtual reality allows users to explore imaginary worlds (virtual world) via head-mounted displays (HMD). HMD encloses the user's sight and auditory 
sensory during the whole experience and makes him deaf and blind to the real world. Because of this isolation, the user becomes an entity inside the virtual world and the level of immersion increases. However, the replacement of human sensory is a double-edged sword; though it provides immersive power to the VR medium, ill-designed experiences may cause unintended consequences such as motion sickness, which is a well-known side effect of VR experiences (e.g., Akiduki et al., 2003; Munafo, Diedrick, and Stoffregen, 2016).

Motion sickness is defined as an illness caused by certain motions (Money, 1970) and is induced by an abnormality in spatial orientation (Reason, 1978). One of the most important prevention methods of motion sickness is the adaptation to spatial changes (Reason, 1978). Virtual reality games have their spatial design, which is different from the real world, and the player should use head and body movements constantly to perceive the virtual environment presented via HMD's. Therefore, it is essential to understand the principles of the game design and perceptual system of humans in relation to the design principles of the VR medium to make a new spatial environment easily adaptable.

Katie Salen and Eric Zimmerman (2004) describe the game as "a system in which players engage in an artificial conflict, defined by rules, that results in a quantifiable outcome", based on analysis of previous definitions from different scholars. As a system, the game contains multiple components, which have international relationships with each other. It provides a context of interactions between spaces, objects, and behaviors that players explore, manipulate, and inhabit. All these interactions happen in a different time, space, and reality of the game, which is called artificiality. Conflict factor in Salen and Zimmerman's definition indicates the obstacles in the game that players must overcome. While trying to overcome these conflicts, rules inform players about what can be and cannot be done. In the end, games have a quantifiable outcome in which players won, lost, or received a score.

The game is an amazingly plastic medium that can be adaptable to any environment and technology (Costikyan, 2002). The main types of games can be listed as physical games, board games, role-playing games, digital games, and virtual reality games. Physical games, as the name suggests, take place in the real world environment with the effort of real physical activities, but are redefined by rules, objects, and boundaries. By this redefinition, they are separated from reality and time (Macklin and Sharp, 2016). Board games have the same design principles as physical games, which are interactions, goals, rules, objects, playscapes, and players. In addition, they are highly affected by physical games in strategy development, gameplay, and simulation. However, also introduce many new elements like discovery, resource management, turn-based play, and dice mechanics (Woods, 2012). Role-playing games are played face-to-face and involve players acting a role in a fictional setting. Players act out within a narrative, either through literal acting or through a process of structured decision-making regarding character development. Board game and physical game elements 
such as discoverability, resource management, strategy development, and puzzle-solving are also used in role-playing games (Cover, 2010).

Different than the other types of games, digital games are named according to the platforms they take place, which are computers, consoles, and mobile and handheld devices. In general, the four traits of digital games make the gaming experience more qualified than other types of gaming experiences. Compared to other types of games, interactivity in digital games very narrow and limited to mouse, keyboard, and controller input and screen and speaker output. However, digital games offer immediate, interactive feedback that allows players to see outcomes of their interactions in no time. Information manipulation in digital games refers to memory management and data usage of graphic outcomes, sounds, the internal logic of the game, and player interactivity. Most of the time, players do not see these information manipulation processes running in the background. Code-based programming of digital games is what makes them automated complex systems. This feature allows the game system to process many tasks in a very short time without interrupting players' gameplay. Networked communication exists in many digital games in different forms like text-based or audio communication, and allows players to interact with each other. Even there is no such direct channel of communication, playing the game together can also be considered as a networked communication (Salen and Zimmerman, 2004).

Virtual reality games are relatively close to digital games from the aspect of the digital medium and requirements. However, virtual reality takes the player, put him in a virtual world via HMD, and give the ability to use physical gestures. Therefore, virtual reality games break the limits of digital games in terms of narrow interactivity. Considering the characteristics of virtual reality games and previously mentioned game types in this article, it can be seen that all game types borrow features from each other, and by so, each game type continues to evolve. Briefly, board games borrow some elements from physical games and add new features to the game, digital games try to simulate other types of games, and virtual reality games try to expand gaming experience that digital games offer. This relationship between different game types is tried to be presented in the figure (Figure 1) below. 


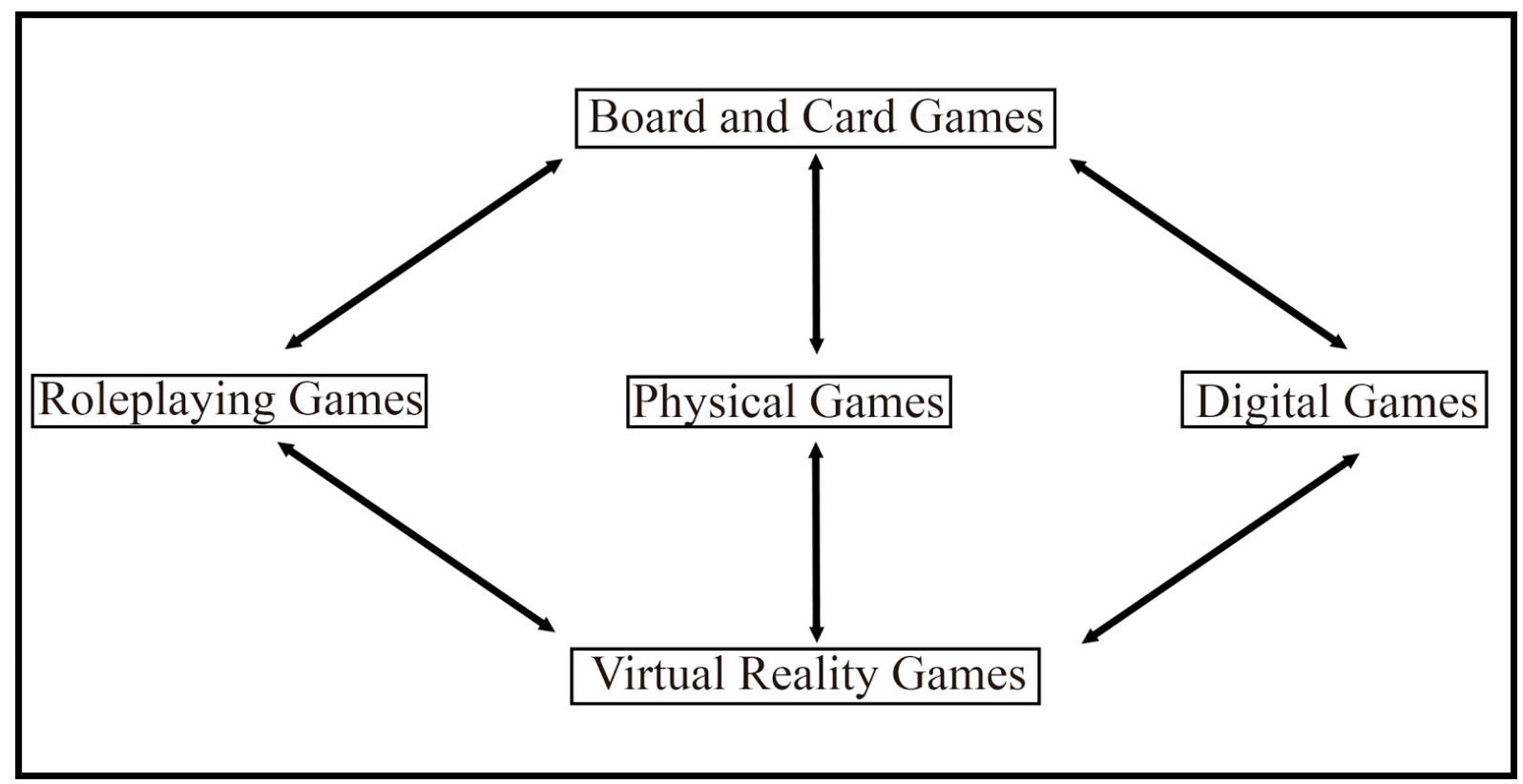

Figure 1. Relationship between game types

Despite their close relationship, the game design process of virtual reality games has far more challenges than digital games due to its immersive power. Making players feel like they are somewhere else and do actions naturally like in the real world requires a match between existing VR technology and game design principles. Indeed VR technology is not a new concept and yet it has shown significant developments only in the last few decades. Today, brands like HTC, Valve, Oculus, and Sony provides several consumer-oriented VR display products in the market. These products have features such as position-tracking system, varifocal technology (wide fields of view), hand scanning, and eye-tracking that provides increased VR and gaming experience. Furthermore, new standalone VR systems, which does not require any computer or mobile phone to work, were released in 2018. These systems have made VR technology more affordable (Virtual Reality Society, 2017).

\subsection{Design Pillars of VR Experience}

Three essential design pillars should be well comprehended before designing virtual reality experiences. These are human perception, interaction, and navigation. In today's technology, only visual, aural, and haptic senses can be implemented to do VR experience design. On the other hand, interaction and navigation features change according to the game design and the experience that is wanted to be given to the player.

\subsubsection{Perception}

The first one is human perception. Understanding how humans perceive reality is important for designing games for any medium, but it is essential for VR (Jerald, 2016). Other mediums such as hand-held applications or console games have screen and input devices (or parts embedded to screen), so the user continues to perceive the surrounding real world while 
experiencing the application or the game. However, the user is partly isolated from the surrounding real world during the VR experience. The level of isolation depends on design choices. The visual sense is the primary sense for designing VR experiences and then comes aural and haptic senses. However, if there is a lack of consistency between senses implemented to the design, the player can feel discomfort and becomes sick (Reason and Brand, 1975).

Design elements for visual senses consist of a field of view (FOV), field of regard (FOR), visual illusions, color, depth, scale, and framing. Current HMD's provide have 100-degree horizontal and 110-degree vertical FOV (Rakkolainen et al., 2017), and 360-degrees horizontal and vertical FOR (Jerald, 2016). Thus, the current VR technology allows the player to look in all directions in the virtual environment by turning his head. Visual illusions help the player to perceive and predict the virtual world faster and provides more room for higher-level processing in the game. Color, shapes, and illumination can be given as examples of sources of visual illusions (Sherman and Craig, 2019). On the other hand, colors has also the power of subconsciously evoking emotions (Clarke and Costall, 2008). Usually, red colors are associated with danger while blue colors are associated with safety, especially in video games. Therefore, different color schemes are used to induce different emotions according to the VR experience desired to be given to the player. Another visual design element scale is used to give a clue about the size of the environment which affects the psychology of the player (Silverman, 2017). A space designed to fit human proportion like houses has a comfortable, natural-feeling but much larger place than human size, like cathedrals or big canyons, evoke the feeling of humbled and smallness.

Depth is another element of visual perception and can be perceived by using distance related information which is called depth cues. Design related depth cues can be listed as monoscopic depth cues, stereoscopic depth cues (stereopsis), and motion depth cues. Monoscopic depth cues depend on a single static view of a scene. These cues are interpositions, shading, size, linear perspective, surface texture gradient, height in the visual field, atmospheric effects, and brightness. Stereoscopic depth cue (stereopsis) is a result of the parallax between the different images received by the retina in each eye, which can be called binocular disparity. Motion depth cue, on the other hand, is the parallax between observer and object created by changing the position of the head or any object (Goldstein, 2014; Sherman and Craig, 2019). These cues help players to determine the location and distance of objects in the game.

In addition to all these elements, framing is also considered as a visual design method at computer games to help the player perceive the world. Designers create the world and interactions like 2D frames. This allows getting the attention of the player for a specific point of interest. However, in VR, the frame is no longer exists. Events not only occur in front of the user but all around the world; therefore, levels should be designed according to the attentional requirements of the game. Focal-based design bases upon this principle. The focal-based 
design alludes to the use of focus points at varying depths in an environment to place objects of interest deliberately to help to establish scale and points of reference in the environment or space that the player occupies (Silverman, 2017).

Aural perception is an extraordinary and complicated system which affected by environment, head pose, physiology, and communication with other sensory modality cues (Jerald, 2016). It is always an open perceptual channel, which means the player cannot avoid the sound (Brewster, 2002). Therefore, VR developers can use sounds to implement essential notifications or events to get the attention of the player because it is guaranteed that the player will sense them. They are also used for setting the mood of the game, which gives an emotional impact on the player (Ekman, 2008). Calm, slow, and natural ambient sounds give the feeling of security and peace, while more aggressive and fast sounds convey danger. Short sound cues, which are called markers, indicate events like a button pressing, a gunshot, or a hitting sound are used to signify interaction of the player with an object in the game world (Parker and Heerema, 2008; Sherman and Craig, 2019). Contrarily, index sounds are continuous sounds indicating certain parameters in the game. Variation in index sounds reflects changes in these parameters (Sherman and Craig, 2019).

Haptic senses have minor roles in VR game design because of complexity to achieve compelling results. They are generally used as feedback elements for touching something or being touched by something in the game (Mihelji and Podobnik, 2012). However, they can also be used as signifiers or depth cues. For instance, a small amount of vibration is given as haptic feedback when the player is far away from the center of the event, and vibration escalates as the player gets closer to the center.

\subsubsection{Interaction}

Interactions can be accomplished by interfaces. Jerald (2016) defines interaction as "the communication that occurs between a user and the VR application that is mediated through the use of input and output devices, and interface as "the VR system side of the interaction that exists whether a user interacting or not". Well-designed interactions help the player to achieve goals of the game efficiently but are also enjoyable to perform and intuitive to fit the mental model of the human. However, the discoverability of interactions in VR is important since the player needs to learn rules of the new virtual world although he has a mental model. Discoverability can be achieved by affordances, signifiers, constraints, and feedback (Norman, 2013) for VR games. Affordance is defined as "the quality or property of an object that defines its possible use or makes clear how it can be used or should be used" (Merriam-Webster, n.d.). It describes a relationship between the user and the properties of a thing in the game or application. Therefore, they should be perceivable due to interaction in the virtual world. Signifiers, on the other hand, inform the user to perceive affordances and figure out how things work. Specific colors or shapes, signs, labels, and images are examples of signifiers. A signifier 
can be known as an existed experience from the player's mind or can be learned in the game. Constraints as another interaction principle for VR interactions are defined as limitations of actions and behaviors, which make interaction design feasible and simplified (Jerald, 2016). They also help to improve the accuracy, precision, and efficiency of the user (Bowman et al, 2004). Constraints are mostly used to limit the number of dimensions for virtual reality interactions. Designers achieve more efficient interactions with these constraints because users cannot always pull the controller in the perfect direction. Constraints can also be used to add more realism to the VR experience. It is vital to use appropriate signifiers to make constraints more perceivable. Lastly, feedbacks are used for informing the user about the results of his or her actions or the status of a task. It helps the player to understand the state of the thing being interacted with, and guides to drive future actions. Feedback can be visual, auditory, and haptic. The essential points in the feedback system are the amount and timing. If feedback is not synchronized with the user's action, it may cause break-in-presence or motion sickness. Also, overused feedback may cause distraction and a lack of perception (Jerald, 2016).

\subsubsection{Navigation}

Navigation is the last design pillar of VR that will be considered in this study. Navigation in VR can be described as "changing the view" and consists of mental and motoric components (Darken and Peterson, 2014). The mental component called "wayfinding" describes methods for making the player aware of where he is located and which path he should follow for the desired destination. It creates a mental model of travel for the player. This mental model involves perception, building a cognitive map of the environment, and planning a path between locations. The player uses personal and environmental wayfinding aids to maintain his perception, to locate attention points (targets), and to plan the route (Darken and Sibert, 1996). Environmental wayfinding aids are mainly blended with the virtual world as roads, building, signs (Pierce and Pausch, 2004) and so, construct scenes. Therefore, they are out of the control of the player. Personal wayfinding aids are tools that participants can use as a guide to find their way in the virtual world. Since they are under the active control of the player, the game should give enough information (signifier) about how to use them unless it is a conscious decision. Many tools or dynamics in VR games can be wayfinding aids; most commons are maps, compasses, changing the view mode (e.g., bird's-eye view), or changing the ability of sight (Sherman and Craig, 2019).

The motoric component of navigation in VR is called "viewpoint control". It is described as the manipulation of the user perspective and includes translocation, orientation, scaling, and travel. Viewpoint control can be categorized under four primary methods which are walking, steering, 3D Multi-touch, and automated transportation. Walking methods mimics "physical walking" in virtual reality systems in various ways (Steinicke et al., 2013). Real walking is one of the most used techniques. In this method, HMD tracks the player's movement and so 
physical movement matches the movement in virtual reality. There is no need for an additional motion tracker unless to show animation for legs in the application with this technique. Walking in place is another technique, which the player should move his body parts (e.g., lifting legs). Therefore, additional trackers are needed for the legs. Theoretically, there is no distance limit for the player in this technique. However, it requires physical effort and so, it is more suitable for small and medium-sized environments. The 3D Multi-Touch methods give the ability of the free movement and control of scaling the world. The player can change positions, orientation, and scale of the world with various gestures of two hands (Marchal et al, 2013). Automated transportation methods change the player's viewpoint without direct control. Passive vehicles can be shown as an example of this method in which the player steps inside or is already seated in the vehicle, and the vehicle moves along a predefined path without control of the player (Sherman and Craig, 2019). Teleportation is the most commonly used automated transportation method, which allows changing the player's location without any motion (Liu et al., 2018). Finally, the steering method describes continuous control of the viewpoint direction. Driving a car or a ship can be shown as steering examples (Bowman et al., 2001).

\section{CASE STUDIES FOR DESIGNING VR GAMES}

This study aims to present a game design guideline for existing VR technologies. For this purpose, five VR games were selected and analyzed for VR design pillars (i.e. perception, interaction, and navigation). These games are Arizona Sunshine, Moos, I Expect You to Die, Superhot and Winlands-2. Each game was chosen according to different perceptual characteristics, interactions, and navigation methods. For analysis, games were played by researchers personally.

\subsection{Arizona Sunshine}

Arizona Sunshine is a story-based, first-person shooter game in the zombie apocalypse theme. The game developed by Vertigo Games and released in December 2016. It is compatible with multiple virtual reality systems such as HTC Vive, Oculus Rift, Playstation VR, and Valve Index. In terms of visual perception, the game has a realistic atmosphere and color usage. Enemies, explosive objects, and collectible items such as ammo and guns have specific colors that help the player to recognize them better. Visual illusions are used to provide a realistic atmosphere. Even there are not too many geometric details in the models, textures and materials give the illusion that these objects look more realistic. As seen in Figure 2 depth cues are used in the game to enhance perception in the following ways:

- Nearby objects are bigger than distant objects.

- Closer objects are masking behind them.

- Distant objects are blurry and less saturated.

- Shadow is existed and gives information about the positional relationship. 
- Distant objects look higher to the player's perspective.

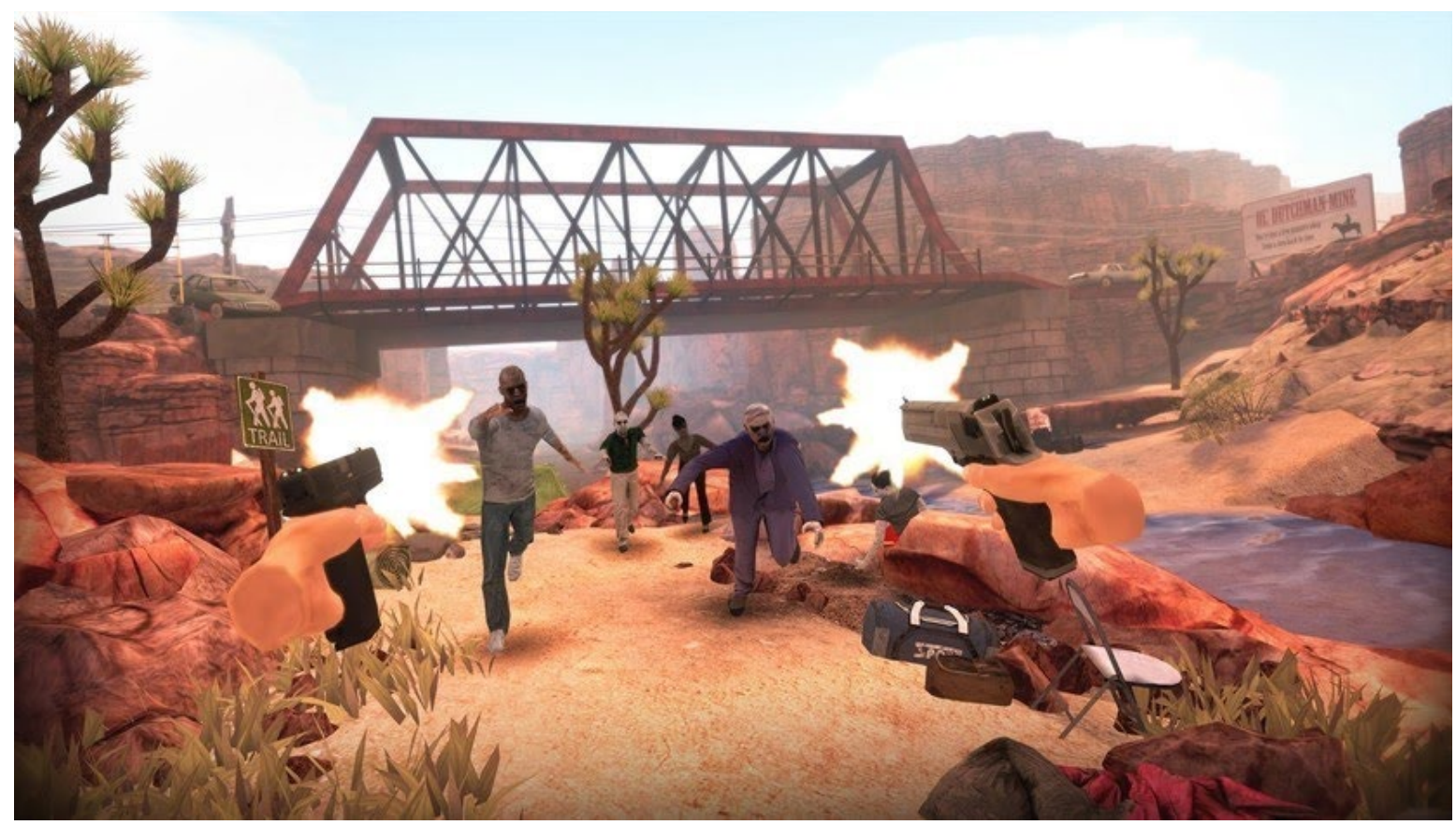

Figure 2. Arizona Sunshine depth cues (Source: https://www.androidcentral.com/arizona-sunshine-launchesoculus-quest-december-5)

For aural perception, the game uses realistic sounds to give information about the environment. Atmospheric sounds such as wind, bird chirpings, and step sounds enhance the immersion. The protagonist is talking by himself which helps the player to emotionally connect with him and to understand the story of the game. Also, marker sounds such as gunfire and explosions are used correctly. Another element is zombie sounds, which help to determine their locations. Zombie sounds also give the feeling of stress and fear for setting the mood of the zombie apocalypse theme. The haptic sensation is used as a feedback element in the game. The vibration of the controller during gunshot or when a zombie hits the player can be given as an example of haptic feedback.

Arizona Sunshine tries to use realistic interaction according to the realistic atmosphere of the game. For this purpose, realistic constraints such as gravity, limitation of ammo, limitation of the health of the player and zombies, and realistic explosions are used. Interaction principles in Arizona Sunshine examined in Table 1.

Table 1 Analysis of interaction principles in Arizona Sunshine 


\begin{tabular}{|c|c|c|}
\hline $\begin{array}{l}\text { Interaction } \\
\text { Principle }\end{array}$ & $\begin{array}{l}\text { Elements of Principle in } \\
\text { the Game }\end{array}$ & Effects on Game and Game Design \\
\hline Affordances & $\begin{array}{l}\text {-Guns } \\
\text {-Ammo } \\
\text {-Enemies } \\
\text {-Stairs, doors } \\
\text {-Explosive objects } \\
\text {-Interactable objects }\end{array}$ & $\begin{array}{l}\text {-Guns and ammo are hidden inside levels. The } \\
\text { player must find them to use. } \\
\text {-Some enemies are slow; some enemies are fast; the } \\
\text { player should navigate places where he/she shoot } \\
\text { them or avoid from them. } \\
\text {-Stairs and doors have usage according to the } \\
\text { mental model of the real world. } \\
\text {-Explosive objects are hidden inside levels; the } \\
\text { player can shoot them for a real damage to multiple } \\
\text { zombies. } \\
\text {-Interactable objects are hidden inside levels; they } \\
\text { are encouraging the player to search levels. }\end{array}$ \\
\hline Signifiers & $\begin{array}{l}\text {-Interactable objects have a } \\
\text { white circle } \\
\text {-Gun has red dot aim } \\
\text { helper } \\
\text {-Ammo belt and Ammo } \\
\text { amounts with different } \\
\text { ammo shapes } \\
\text { - Gun model and sound for } \\
\text { empty gun } \\
\text {-Animated arrow for stairs } \\
\text {-Signs around the world } \\
\text {-Generic shape and noises } \\
\text { for enemies }\end{array}$ & $\begin{array}{l}\text {-All interactable objects must have white circles, but } \\
\text { some of them are missing. } \\
\text {-The player should look down to check his ammo } \\
\text { from time to time; he can understand types of ammo } \\
\text { from shapes. } \\
\text {-The player can understand when the gun is empty } \\
\text { from its shape and sound. } \\
\text {-The player knows which places can be climbable } \\
\text { and which are not. } \\
\text {-Signs are helpful to navigate in the game } \\
\text {-The player knows who the enemy is }\end{array}$ \\
\hline Constraints & $\begin{array}{l}\text {-Gravity. } \\
\text {-Maximum teleport } \\
\text { distance } \\
\text {-Some areas are not able to } \\
\text { teleportation. }\end{array}$ & $\begin{array}{l}\text {-Gravity adds realism to the game. } \\
\text {-Limiting teleport distance is helpful to control the } \\
\text { navigation. }\end{array}$ \\
\hline
\end{tabular}




\begin{tabular}{|l|l|l|}
\hline & -Cant teleport inside objects & $\begin{array}{l}\text {-Limiting the teleportation area helps keep the } \\
\text { player inside the predefined path of the game and } \\
\text { avoid bugs. }\end{array}$ \\
\hline Feedbacks & $\begin{array}{l}\text {-Ammo Belt } \\
\text {-Digital Watch } \\
\text {-Enemy noises } \\
\text {-Firing animation and noise } \\
\text {-Dropping magazine } \\
\text {-Empty weapon model, } \\
\text { sound, and animation. } \\
\text {-Available to teleport mark } \\
\text {-Not available to teleport } \\
\text { mark }\end{array}$ & $\begin{array}{l}\text {-Ammo belt and the digital watch is intuitive for } \\
\text { interface design also add the fun factor to the game. } \\
\text { The player gets information from these tools. } \\
\text {-Destination marks give feedback about the selected } \\
\text { area is available to teleport or not. }\end{array}$ \\
\hline
\end{tabular}

Arizona sunshine uses two different navigation methods. The first one is teleportation and the second one is the steering method. Both methods allow navigating inside large levels of the game. However, the steering method can cause motion sickness due to the misorientation of the vestibular perceptual system of humans. The teleportation method might be more suitable for long play hours.

\subsection{Moss}

Moss is an action-adventure puzzle game that combining combat and world exploration. Moss is developed by studio Polyarc and released for Playstation VR and Microsoft Windows in February 2018 and June 2018, respectively. It has a two character control system. The first character is a mouse named Quill, who can walk, run, jump, and climb in the environment and fight with enemies. The second character is the human-sized reader who controlled by the player from the perspective of the first-person. This character is like a guide for Quill, who helps her to overcome puzzles of the game, and heal her when she is wounded.

One of the important aspects of visual design choices of Moss is scale differences between the reader and Quill. As seen in Figure 3, the player sees from the view of the reader who is in the shape of the spirit of the forest, a mighty entity that has control over the world. Designers 
evoke this feeling with the size of levels, environmental depth, and eye-level inside the world. Also, Quill seems very tiny inside this big world and so the player can feel how weak and needy she is. The player does not see the world from her perspective but still can understand by getting closer to her and look at the world from that low-level perspective. The game also uses color cues in the game as red indicates danger, green indicates health and, blue indicates safety. In addition, dark and bright areas are used to focus the attention of the player.

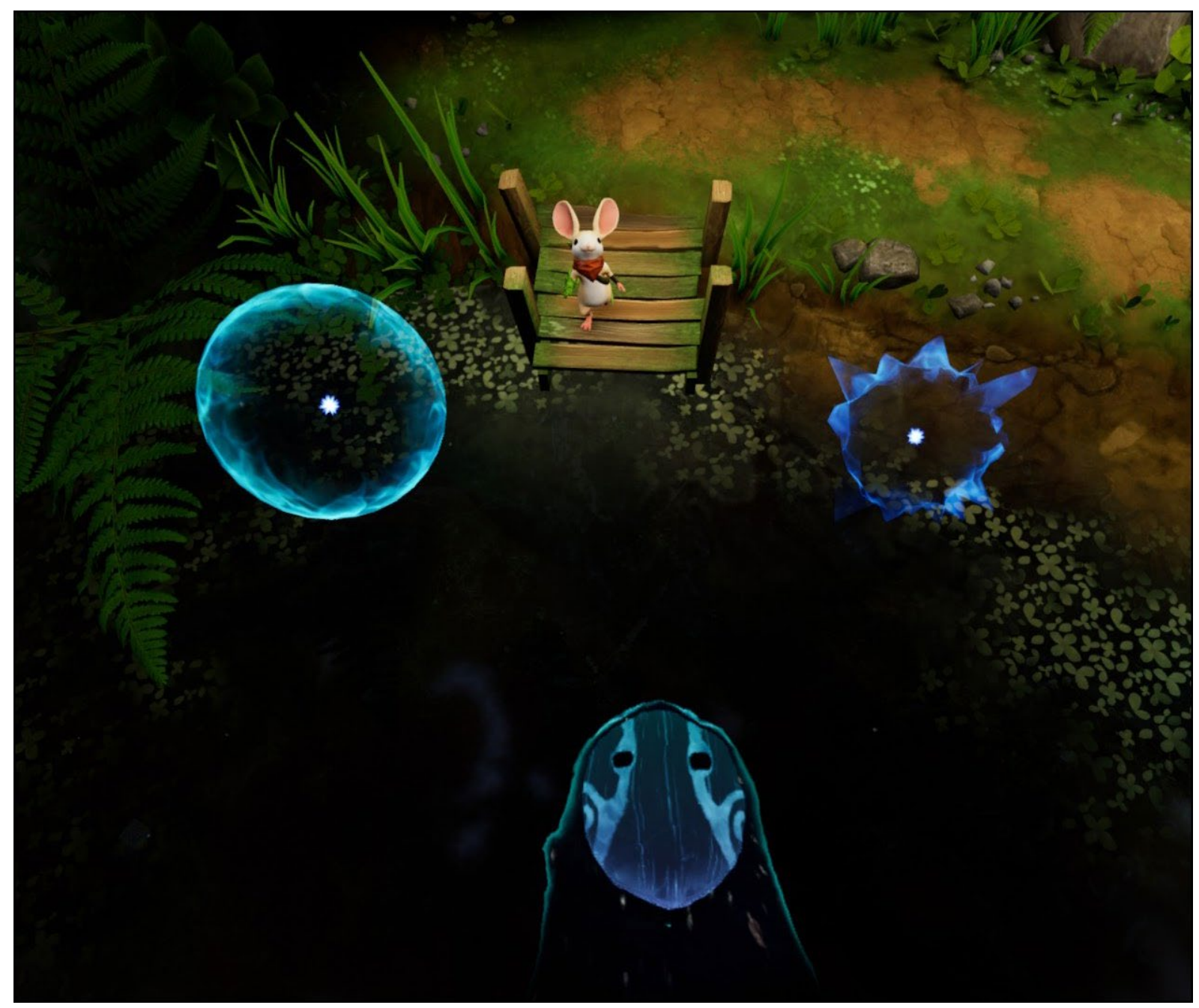

Figure 3. Playable characters of Moss VR game

Aural perception cues are used for getting the attention of the player. As an example, Quill makes sounds while moving or trying to do something, and so, the player can focus his attention on what Quill is doing. Sound is also used as an environmental background for setting a magical story mood.

Interactions in Moss is intuitive and fit the mental model of human perception. Most of the interactions are related to rotating, pulling, or pushing objects which adds the fun factor to the game. On the other hand, the direction of movements is restricted to one axis, which adds a constraint element to the game design. Designers achieve efficient interactions by these 
constraints because players cannot always pull the controller in the perfect direction. All interaction principles of Moss can be seen in Table 2.

Table 2 Analysis of interaction principles in Moss

\begin{tabular}{|c|c|c|}
\hline Interaction Principle & $\begin{array}{l}\text { Elements of Principle } \\
\text { in the Game }\end{array}$ & Effects on Game and Game Design \\
\hline Affordances & $\begin{array}{l}\text {-Platforms } \\
\text {-Collectables } \\
\text {-Destructible objects } \\
\text {-Enemies } \\
\text {-Sword } \\
\text {-Interactable objects } \\
\text {-Blockers }\end{array}$ & $\begin{array}{l}\text {-Quill must pass platforms to reach } \\
\text { the next level. The player must find } \\
\text { ways to pass them. } \\
\text {-Collectible and destructible objects } \\
\text { are encouraging the player to search } \\
\text { levels. } \\
\text {-Sword is the only weapon also it can } \\
\text { destroy some blockers. } \\
\text {-Most of the interactable objects are } \\
\text { glowing so the player knows to } \\
\text { interact with them somehow. These } \\
\text { objects can be blockers or a key to } \\
\text { solving puzzles. }\end{array}$ \\
\hline Signifiers & $\begin{array}{l}\text {-Scratched parts for } \\
\text { climbable areas } \\
\text {-Sliding marks at surfaces } \\
\text { for these types of } \\
\text { interactions. } \\
\text {-Music changes when an } \\
\text { enemy near. } \\
\text {-Interactable objects have a } \\
\text { glowing effect but still, } \\
\text { some objects do not glow. }\end{array}$ & $\begin{array}{l}\text {-The player can find the solution of } \\
\text { puzzles with the help of signifiers. } \\
\text {-The player is alerted for enemies } \\
\text { because of the music. } \\
\text {-The game encourages the player to } \\
\text { search the areas and break the objects } \\
\text { for a prize. Some of the not glowing } \\
\text { objects are breakable and when } \\
\text { broken the player gets points. }\end{array}$ \\
\hline Constraints & $\begin{array}{l}\text {-Quill cannot swim in the } \\
\text { water. } \\
\text {-Axis constraints for sliding } \\
\text { puzzles }\end{array}$ & $\begin{array}{l}\text {-Levels are designed with water and } \\
\text { gaps so for Quill part these constraints } \\
\text { make the game as a platformer. } \\
\text {-Sliding constraints makes interaction } \\
\text { easier for the player. }\end{array}$ \\
\hline
\end{tabular}




\begin{tabular}{|l|l|l|}
\hline & $\begin{array}{l}\text {-High jump does not hurt } \\
\text { Quill } \\
\text {-Gravity and mass are } \\
\text { realistic. }\end{array}$ & -Gravity and mass are part of puzzles. \\
\hline Feedbacks & $\begin{array}{l}\text {-Quill's color changes } \\
\text {-Ghostling when Quill is } \\
\text { behind an object. } \\
\text {-Quill's hearth beat faster } \\
\text { when she is scared }\end{array}$ & $\begin{array}{l}\text {-Quill's color changes to red when she } \\
\text { hurts and turns to normal when } \\
\text { healed by the player. } \\
\text {-Ghostling is helpful to see Quill when } \\
\text { she behind and object. } \\
\text {-Quill's heartbeat can be sensed by } \\
\text { haptics, it is connecting the player to } \\
\text { Quill emotionally and helps to } \\
\text { understand dangers. }\end{array}$ \\
\hline
\end{tabular}

Because of the two-character control, Moss has two different navigation methods. Quill's navigation is more simplistic that consist of button related arrows or touchpad directions for movement and defined buttons for jump and interaction. Other character Reader does not change active location but can change view height, perspective, and rotation with the trackers of virtual reality systems. Therefore, the game has small gameplay areas at each level. Quill and Reader solve puzzles, overcome obstacles, and defeat enemies at these little stages; after each scene, a new one appears as related to the previous one. Therefore, the player can connect scenes in a continuous path. Most of the cases the player can see other scenes at the current scene. This design choice enhances the presence in the game.

\subsection{Expect You to Die}

I Expect You to Die is a first-person perspective puzzle game. The game developed by Schell Games and released in 2016 for Playstation VR and Microsoft Windows. The game can be played using the HTC Vive, Playstation VR, Oculus Rift, and Quest. In the game, players should solve puzzles with the help of telekinetic abilities as a "James Bond-esque" spy. Each level has different styled puzzles therefore different interactions and obstacles. Most of the puzzles are time-based and most of the "hints" try to defeat the player intentionally. Because of the intentionally defeating strategy of the game, the player often dies and start over the same level again and again.

The game has a realistic styled visual design. Small levels evoke the feeling of claustrophobia and desire to go out quickly. Audio and voice designs support these principles. Game music tries to induce the feeling of a spy movie and helps the player to feel like an actual spy. In addition, the music evokes the feeling of the rush and danger during the appropriate phases 
of puzzle-solving. Tic-tac sound from a timed bomb for example is used as an index sound and aims to speed up the player. Depth cues also used appropriately in-game with colors, light, shadow, and accurate object sizes.

Interaction in the game mostly fits the mental model of a human. Most of the interactions mimic real-world interactions except telekinetic ability. This ability allows the player to reach out to distant objects because the game is played in a still position. Also, the player has a special ability that can be called cancelation of gravity. It allows the player to hang objects in the air near himself. In this way, hanged objects become easily reachable. All interaction principles of the game can be seen in Table 3.

Table 3 Analysis of interaction principles in I Expect You to Die

\begin{tabular}{|c|c|c|}
\hline $\begin{array}{l}\text { Interaction } \\
\text { Principle }\end{array}$ & $\begin{array}{l}\text { Elements of Principle } \\
\text { in the Game }\end{array}$ & Effects on Game and Game Design \\
\hline Affordances & $\begin{array}{l}\text {-Objects } \\
\text {-Notes } \\
\text {-Quests }\end{array}$ & $\begin{array}{l}\text {-Each level has specific objects, the player should use } \\
\text { them to solve puzzles. } \\
\text {-Some objects are only distractions. } \\
\text {-Notes are helpful to solve puzzles but also some of } \\
\text { them are distractions. } \\
\text {-Each level has a unique quest; the player should solve } \\
\text { the puzzle to reach the next level. }\end{array}$ \\
\hline Signifiers & $\begin{array}{l}\text {-Interactable objects } \\
\text { have a glowing effect. } \\
\text {-Existed knowledge of } \\
\text { objects (e.g., lighter, } \\
\text { gun, knife) } \\
\text {-Music changes when } \\
\text { something triggered. } \\
\text {-Notes for some guides } \\
\text {-Hand model changes } \\
\text { when near the } \\
\text { interactable objects. }\end{array}$ & $\begin{array}{l}\text {-The player can find the solution of puzzles with the } \\
\text { help of signifiers. } \\
\text {-The Player understands something happens when } \\
\text { music changes } \\
\text {-Notes can be misleading. The game is always trying to } \\
\text { kill the player with misleading information; therefore, } \\
\text { the player should always try and learn what the correct } \\
\text { solution is. }\end{array}$ \\
\hline
\end{tabular}




\begin{tabular}{|l|l|l|}
\hline Constraints & $\begin{array}{l}\text {-Gravity exists but in } \\
\text { control of the player. } \\
\text {-Distant objects are } \\
\text { reachable. }\end{array}$ & $\begin{array}{l}\text {-Too many objects to use in levels, with hanging object } \\
\text { players, can easily find objects when needed. } \\
\text {-Players can't navigate in levels, so distant reachability } \\
\text { is one the main feature of the game design. }\end{array}$ \\
\hline Feedbacks & $\begin{array}{l}\text {-Music } \\
\text {-Voice acting } \\
\text {-General animations } \\
\text { according to } \\
\text { interactions. }\end{array}$ & $\begin{array}{l}\text {-Music changes when part of the puzzle solved. } \\
\text {-Voice acting can speak from time to time to give } \\
\text { information or warnings. } \\
\text {-General animations simulate the real world; therefore, } \\
\text { the player can understand what they are doing. E.g., } \\
\text { lighter get fire when opened. }\end{array}$ \\
\hline
\end{tabular}

I Expect You To Die does not have an active navigation system. The game only uses the field of view control, which can be achieved by rotation of the head and leaning. Because of no active navigation system, the game has small levels. Most of the items are reachable but to reach out to distant objects, players can use the telekinetic ability. The game does not cause motion sickness due to a lack of navigation system and can be played for long hours without motion sickness.

\subsection{Superhot}

Superhot is a first-person shooter game. The game has a special feature that time moves when the player moves. The game was developed by Superhot Team and released for Oculus Rift in 2016, and for HTC Vive in May 2017. The game has a stylized visual design that uses only three colors. Red color represents the enemy, black color represents weapons and objects that can be used as a weapon and white color represents the solid surfaces that can be used as covers. Although the game has small levels it uses depth cues for immersion and presence: enemies look bigger when they come near to the player, distant objects look less saturated and blurry, objects and enemies in front are masking what is behind them. Audio and sounds are used minimal but appropriate according to the situation. Marker sounds like gunshot or hitting are fitted to perceptual senses. Haptic senses are only used as feedback of superpower in the game.

The interaction design used in the game has similar but not the same with real-world representations. Therefore, the player should develop new mental models in the game based on his real-world experiences. There is three different interaction system for weapons: grabbing, firing, and throwing. All interaction principles for Superhot can be seen in Table 4 .

Table 4 Analysis of interaction principles in Superhot 


\begin{tabular}{|c|c|c|}
\hline $\begin{array}{l}\text { Interaction } \\
\text { Principle }\end{array}$ & $\begin{array}{l}\text { Elements of Principle in the } \\
\text { Game }\end{array}$ & Effects on Game and Game Design \\
\hline Affordances & $\begin{array}{l}\text {-Weapons } \\
\text {-Enemies } \\
\text {-Explode Ability }\end{array}$ & $\begin{array}{l}\text {-Each weapon has specific features. For } \\
\text { instance, the pistol can shoot five times, but } \\
\text { shotgun has only two ammo. } \\
\text {-Enemies have specific positions inside levels. } \\
\text { The players should find them before they kill } \\
\text { the player. } \\
\text {-Last levels player gets new power, which is } \\
\text { the explode ability. These levels have specific } \\
\text { puzzles according to the new ability }\end{array}$ \\
\hline Signifiers & $\begin{array}{l}\text {-Red colors for enemies } \\
\text {-White colors for noninteractive } \\
\text { objects but usable for blocking } \\
\text { bullets } \\
\text {-Black colors for interactable } \\
\text { objects. } \\
\text {-Firing guns and throwing objects } \\
\text { mechanics uses existed } \\
\text { knowledge of humans. }\end{array}$ & $\begin{array}{l}\text {-Players can easily understand which colors } \\
\text { indicate which types of objects. } \\
\text {-The mental model fits for interactions. }\end{array}$ \\
\hline Constraints & $\begin{array}{l}\text {-Gravity exists } \\
\text {-Slow time mechanic } \\
\text {-Limited ammo for each gun type } \\
\text {-One hit to kill and one hit to die }\end{array}$ & $\begin{array}{l}\text {-Gravity can be used for throwing objects and } \\
\text { empty guns. } \\
\text {-Slow time is the main mechanic of the game. } \\
\text {-Limited ammo force the player to make } \\
\text { strategy and change weapons } \\
\text {-One hit to kill and die force to player use the } \\
\text { slow time mechanic and make strategies. }\end{array}$ \\
\hline Feedbacks & $\begin{array}{l}\text {-Sounds Audio } \\
\text {-Words } \\
\text {-Hand animation when a bullet } \\
\text { caught or power used. }\end{array}$ & $\begin{array}{l}\text {-Game sound like a gunshot or hitting sounds } \\
\text { gives feedbacks about these interactions. } \\
\text {-Words are appearing to guide the player. } \\
\text {-Hand animation tells that one cannot use } \\
\text { power and cannot catch a bullet again before } \\
\text { the hand animation turns to normal. }\end{array}$ \\
\hline
\end{tabular}

Superhot uses real movement as a method of navigation. The player should use his body to avoid being shot or reaching out to objects. Therefore, the game has small levels, and objects are always in reach. It uses FOV and FOR appropriately; the player should look at all directions 
to see weapons and avoid bullets. The game does not cause motion sickness due to the real body movements which are synchronized with the human vestibular system.

\subsection{Windlands 2}

Windlands 2 is a first-person grappling hook exploration game. The game was developed by Psytec Games and released in 2018. It allows the player to roam freely with a grappling hook in an open world. Therefore, it has a massive level of design. It has a stylized, cartoonish graphic design with a vibrant color scheme. Colors address different things in the game. For example, green bushes show places where the player can hook, red color informs about the danger and weak spots of enemies, yellow light beams show the checkpoint areas, and so on. Windlands 2 uses depth cues in a way similar to the Arizona Sunshine: distant areas are less saturated and covered with fog, nearby objects look much bigger and detailed, texturing on the objects is more distinct when they are closer.

Sound and audio design are also important for Windlands 2. Environmental music in the background helps to set the relaxing mood of the game. This music changes when enemies are nearby which serves as an alert of danger for the player. Also, the voice acting is used to guide the player. When the player is closer to NPCs, he hears their voice directly and when they go away, he hears their grappling hook devices (like a mobile phone).

Windlands 2 has a unique interaction method, which is a navigation method at the same time. The player uses the grappling hook to navigate in the world but it can also be used for fighting with enemies. There is also a bow item in the game. Bow shooting mimics the real bow shooting behavior. Hence, it is suitable for the mental model of humans and easily understandable. All interaction principles of Windlands 2 can be seen in Table 5 .

Table 5 Analysis of interaction principles in Windlands 2

\begin{tabular}{|l|l|l|}
\hline $\begin{array}{l}\text { Interaction } \\
\text { Principle }\end{array}$ & $\begin{array}{l}\text { Elements of Principle in } \\
\text { the Game }\end{array}$ & Effects on Game and Game Design \\
\hline Affordances & $\begin{array}{l}\text {-The Hook } \\
\text {-The Bow } \\
\text {-Bushes } \\
\text {-Gaps, platforms } \\
\text {-NPC's } \\
\text {-Enemies } \\
\text {-Quests } \\
\text {-Collectables }\end{array}$ & $\begin{array}{l}\text {-The hook is one of the navigation methods in the } \\
\text { game. The player should aim to bushes to swing } \\
\text { around the levels. } \\
\text {-With low gravity and hook, players pass through } \\
\text { gaps and platforms. } \\
\text {-NPC's have quests player should talk with them to } \\
\text { get quests. } \\
\text {-Collectables hidden inside the world, it is } \\
\text { encouraging the player to search in levels. }\end{array}$ \\
\hline
\end{tabular}




\begin{tabular}{|l|l|l|}
\hline Signifiers & $\begin{array}{l}\text {-Green Bushes. } \\
\text {-Hook's red dot. } \\
\text {-Bow mechanic uses } \\
\text { existed knowledge like a } \\
\text { real bow } \\
\text {-Weak spots for enemies. } \\
\text {-Destination point and } \\
\text { meter } \\
\text {-Different color codes for } \\
\text { objectives. }\end{array}$ & $\begin{array}{l}\text {-Player easily understand where to hook because of } \\
\text { green bushes } \\
\text {-Hook's red dot makes it easier to aim and shot } \\
\text {-Destination points help the player to find the way } \\
\text {-The world is big so different colors of objectives } \\
\text { make it easier to find them }\end{array}$ \\
\hline Constraints & $\begin{array}{l}\text {-Gravity is less effective } \\
\text { for jumps } \\
\text {-Swing angle cannot go } \\
\text { beyond a certain amount } \\
\text {-The hook cannot go } \\
\text { beyond a certain amount }\end{array}$ & $\begin{array}{l}\text {-Because of less gravity, long gaps exist in the game. } \\
\text {-If the swing angle does not be limited player would } \\
\text {-Hoch does not go to infinite because of the fall } \\
\text { mechic in the game. Complex hook points make } \\
\text { the game more challenging. }\end{array}$ \\
\hline Feedbacks & $\begin{array}{l}\text {-Music and audio } \\
\text {-NPC talkings } \\
\text {-Enemy animations }\end{array}$ & $\begin{array}{l}\text {-Music and audio synchronized with the mood of } \\
\text { the game. When in danger, music changes. } \\
\text {-NPC talkings are helpful to the player } \\
\text {-Enemy animations change when they are hurts }\end{array}$ \\
\hline
\end{tabular}

Windlands 2 has two navigation methods in the game: steering method and swinging with the grappling hook. These navigation methods help the player navigate inside larger levels of the game. However, larger levels come with additional challenges like wayfinding and discoverability. Windlands 2 uses both environmental and personal wayfinding aids. Green trees as grappling hook points can be an example of environmental wayfinding aids. They indicate path choices to the player that he can go on. On the other hand, distance meters and yellow beams for destination points are examples of personal wayfinding aids. The game also has different colored beams for quests, enemies, and collectible items as a part of its visual design.

Navigation is one of the most essential aspects of this game but it can also cause motion sickness. To avoid it, the game offers comfort settings that can be set individually for different players. These settings include limitation of turning amount, different comfort cage settings around the player, vignette effects, and standing markers. Options of comfort settings can be seen in Figure 4. 


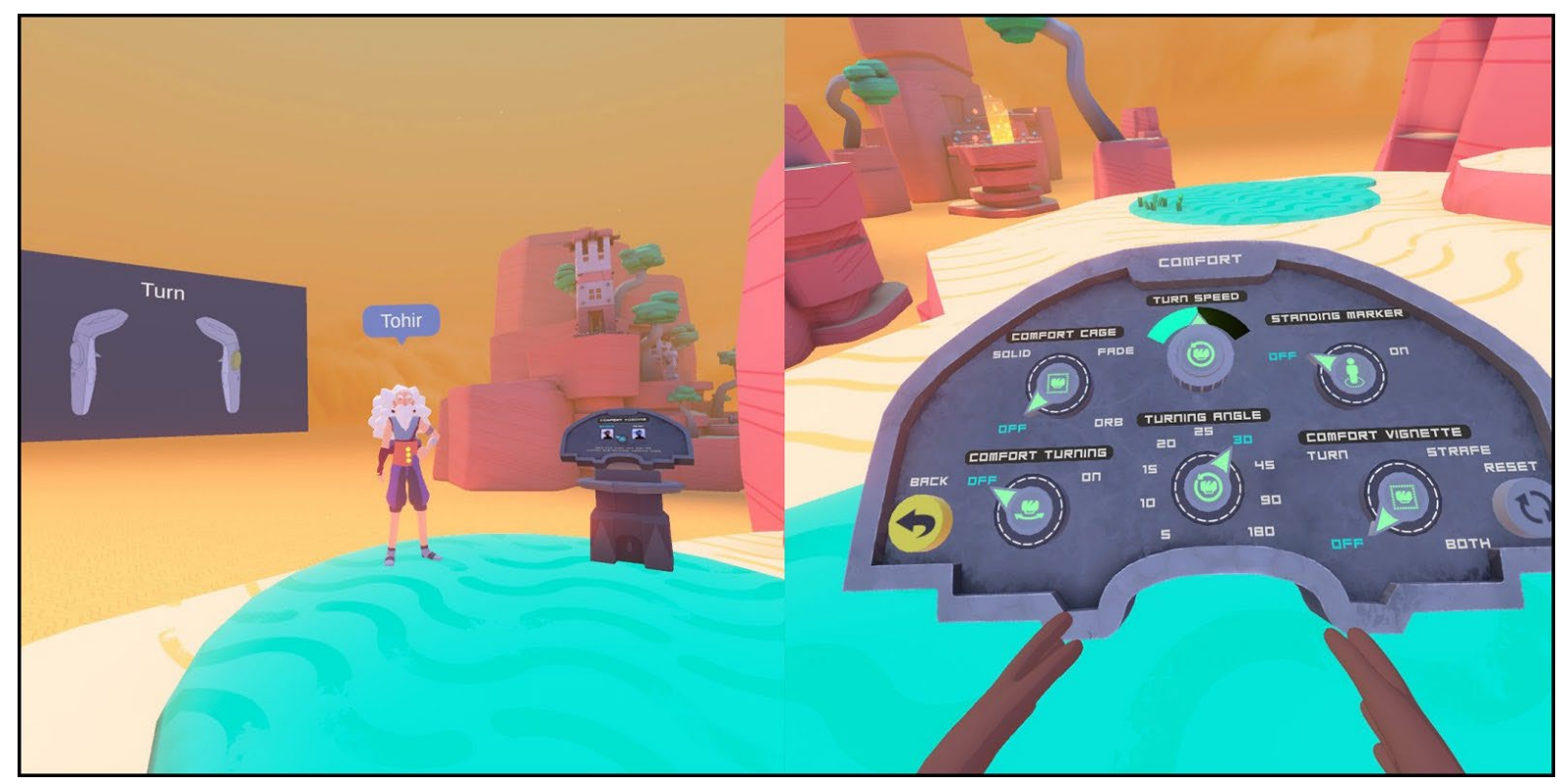

Figure 4. Windlands 2 VR game navigation method options

\section{A DESIGN GUIDELINE FOR VIRTUAL REALITY GAMES}

Analyses of five VR games in terms of game design elements and design pillars of VR experiences shows that designing for the human is essential as in many other mediums. However, the VR medium offers many possibilities and limitations to designers that can be implemented in each VR game differently. Therefore, a guideline is framed based on the analysis of this study for the identification of core elements in VR game design. Guideline elements are listed below according to three design pillars:

\section{Perceptual Design Guideline:}

- Virtual reality has 360-degree FOR, so attraction points must be used to get the attention of the user. These attraction points can be visual or auditory.

- $\quad$ Human perception has variations from person to person, so iteration in levels by playtests is essential. Regular VR players are different from new VR players, different types of player should use in playtests.

- $\quad$ Understanding visual illusions are beneficial for game designers in many ways. Virtual reality games need low polygon models due to hardware requirements. Therefore, game designers should use visual illusions on models.

- $\quad$ To provide depth in levels, a decent number of depth cues should be used. The visual style, realism, and the field of view can affect depth cues.

- $\quad$ Auditory and haptic design features can also be used as depth cues along with visual depth cues. The sound level can change due to the player location inside the virtual world. The haptic sensation can be used as a depth cue with the vibration level linked to the player location. 
- $\quad$ Colors can be used to evoke different emotions. The most commonly known effects of colors are feeling of danger for red, feeling of hazard for green, and safety for blue safety.

- $\quad$ Sensory cues must be consistent with each other. For example, the animation of a gunshot should match the sound and, if any, haptic feedback.

- $\quad$ The scale is vital to perceive the world and for an emotional experience. Small and claustrophobic environments provide a sense of might but also uncomfortable feelings. On the other hand, large and open environments provide a sense of smallness and humbleness but also give comfortable feelings.

- $\quad$ Audio is essential to create an immersive experience, especially when it is used binaural to give a sense of the base location of the sound and spatialization of the environment. Indoor and outdoor sounds are not perceived as the same, so game designers should consider this difference while designing the game.

\section{Interactional Design Guideline:}

- Intuitive interaction designs easily fit the mental models of players. For example, shooting gun interaction in most VR games uses the trigger button to simulate real gun shooting.

- Interaction methods must be consistent throughout levels. Consistency is necessary for all games, but it is essential for VR games. It is because VR is a fullbody experience. If things keep changing between levels, players may lose orientation.

- $\quad$ Signifiers should be easily perceivable by users, but too many signifiers can be confusing. Therefore, they must be used in the proper amount.

- Constraints must be used where appropriate. If constraints are not used appropriately, they make it harder to complete interactions.

- Constraints can be both realistic and unrealistic.

- $\quad$ Feedbacks are essential for effective interactions. However, designers should be careful not to use too much feedback which would overwhelm the player.

\section{Navigational Design Guideline:}

- Using the appropriate navigation method for the game is essential and should be decided at the early stages of game design.

- $\quad$ Playtests are important due to motion sickness effects for various users. Motion sickness effects can vary from person to person. A person who plays the VR game for the first time will be more affected more than a regular VR player will. Designers cannot tell the effects of motion sickness due to lots of iteration and 
usage of the VR, so playtests with different types of players will be helpful to reduce motion sickness effects in games.

- Walking methods should be used in small levels. The real walking method is dependent on the tracking area of the VR system. Therefore, levels should be designed at the reach of the player. Walking in place is theoretically independent of the tracking area, but it is a physical activity so game designers should not forget this factor while designing games. Teleportation and steering methods are suitable for vast game level distances.

- $\quad$ Fading in and out should be used in the teleportation method due to miss orientation. Teleportation is a sudden change of location so the player can be disoriented. Fading effects are helpful to slow down the teleportation process.

- $\quad$ Signifiers used as visual navigation cues help the player to perceive the designated location during the teleportation. These signifiers can be exemplified as a beam, an arrow to show where is the point of view, and a square for the teleportation area.

- $\quad$ Rotational constraints can be used in steering methods to reduce motion sickness. Motion sickness does not affect everyone in the same way. Therefore, comfort settings are useful for players to set their personal preferences. In this way, they may experience any motion sickness effect or minimum amount of it while playing the game.

- $\quad$ Steering methods can cause motion sickness if visual sight and the vestibular system do not match. Constant velocity during the navigation and instantaneous acceleration in the starting and ending periods of the navigation is helpful to avoid motion sickness.

\section{DISCUSSION}

The current study presents a guideline for designing VR games according to case studies and literature review. For each design pillars (perception, interaction, and navigation), different guidelines have been created. Instead of focusing on one particular game type, general principles of virtual reality games were considered while designing the guideline. Thus, five VR games with different design features were analyzed according to the design pillars of VR experiences and game design principles as a foundation of this study. The results indicate that each game type has unique features but also common principles. Being artificial, interactive, and rule-based and having a quantifiable outcome are common principles of games. On the other hand, the game medium should be considered while designing a game. As an instance, a board game does not evoke the same feeling if adapted to the digital medium. Likewise, a digital game cannot be adapted to virtual reality in the same way. While digital games are played on screen with input devices such as a keyboard, mouse, or controller, virtual reality games are played physically and create immersion in the virtual world. 
Virtual reality takes the player into a virtual world where he can physically manipulate, interact with, and navigate. It should be recognized that the virtual world and real-world have similarities in terms of visual, aural, and haptic perception. Also, the most efficient interactions are the ones that fit the mental model of humans because they base on existed knowledge. Therefore, players can more easily recognize and perform them. On the other hand, navigation is always a challenge while designing virtual reality games due to the risk of motion sickness effects. Especially, steering methods should be used in caution. Constant velocity during the movement and minimum acceleration at the start and the end of the movement should be used to minimize motion sickness.

This study is based on the current state of virtual reality systems. However, they continue to evolve every day with new technologies. As an instance, many more HMD devices and virtual reality systems released such as Valve Index and HTC Vive Cosmos during the period of this study. Valve Index has advanced finger-tracking systems on the controllers and changes the interaction possibilities entirely for virtual reality games. Therefore, it is essential for a game designer to follow those technological advancements in VR systems and adapt their designs to increase the game experience of players. In addition, scholars should regularly update knowledge on the effects of new VR technologies on players to identify possible advancements and limitations.

The proposed guideline only proposes a route for VR game designers. However, there is a need for further studies to understand the advantages of the proposed guideline. Therefore, a comparative study between a VR game that would be designed according to the proposed guideline and existed VR games are suggested to be conducted in further studies. In addition, those studies would be beneficial for the improvement of the proposed guideline to obtain better player experience results in future VR games.

\section{REFERENCES}

Merriam-Webster. (n.d.). Affordance. In Merriam-Webster.com dictionary, Retrieved July 1, 2020, from https://www.merriam-webster.com/dictionary/affordance.

Akiduki, H., Nishiike, S., Watanabe, H., Matsuoka, K., Kubo, T., \& Takeda, N. (2003). Visual-vestibular conflict induced by virtual reality in humans. Neuroscience Letters, 340, 197-200.

Bowman, D. A., Kruijff, E., LaViola Jr, J. J., \& Poupyrev, I. (2001). An introduction to 3-D user interface design. Presence: Teleoperators \& Virtual Environments, 10(1), 96-108.

Bowman, D. A., Kruijff, E., LaViola, J., Jr., \& Poupyrev, I. (2004). $3 d$ user interfaces: theory and practice. Addison-Wesley.

Brewster, S. A. (2002). Non-speech auditory input. In J. A. Jacko, J. A., \& A. Sears (Eds.), Human-computer interaction handbook (pp. 220-239). Mahwah, NJ.: Lawrence Erlbaum Associates. 
Clarke, T. \& Costall, A. (2008). The emotional connotations of color: qualitative investigation. Color Research \& Application: Endorsed by Inter-Society Color Council, The Colour Group (Great Britain), Canadian Society for Color, Color Science Association of Japan, Dutch Society for the Study of Color, The Swedish Colour Centre Foundation, Colour Society of Australia, Centre Français de la Couleur, 33(5), 406-410.

Cover, J. G. (2014). The creation of narrative in tabletop role-playing games. North Carolina, USA: McFarland \& Company Inc.

Costikyan, G., (2002). I have no words \& I must design: toward a critical vocabulary for games. In Proceedings of the computer games and digital cultures conference (pp. 9-33). Finland: Tampere University Press.

Darken, R. P., \& Sibert, J. L. (1996). Wayfinding strategies and behaviors in large virtual worlds. CHI '96, 142-149.

Darken, R. P., \& Peterson, B. (2014). Spatial orientation, wayfinding, and representation. In K. S. Hale \& K. M. Stanney (Eds.), Handbook of virtual environments (2nd ed., pp. 467-491). Boca Raton, FL: CRC Press.

Ekman, I. (2008). Psychologically motivated techniques for emotional sound in computer games. In Proceedings AudioMostly (pp. 20-26). Sweden.

Goldstein, E.B. (2014). Sensation and perception (9th ed.). Belmont, CA: Wadsworth, Cengage Learning.

Jerald, J. (2016). The VR Book: Human-centered design for virtual reality. Morgan \& Claypool Publishers.

Liu, J., Parekh, H., Al-Zayer, M., \& Folmer, E. (2018). Increasing walking in VR using redirected teleportation. In Proceedings of the 31st annual ACM symposium on user interface software and technology (pp. 521-529).

Macklin, C., \& Sharp, J. (2016). Games, design and play: A detailed approach to iterative game design. AddisonWesley Professional.

Marchal, D., Moerman, C., Casiez, G., \& Roussel, N. (2013). Designing intuitive multi-touch 3d navigation techniques. In IFIP conference on human-computer interaction (pp. 19-36). Springer.

Mihelji, M., \& Podobnik, J. (2012). Haptics for virtual reality and teleoperation (Vol. 67). Springer Science \& Business Media.

Money, K. E. (1970). Motion sickness. Physiological Reviews, 50(1), 1-39.

Norman, D. A. (2013). The design of everyday things, expanded and revised edition. Human factors and ergonomics in manufacturing. New York: Basic Books.

Parker, J. R. \& Hereema, J. (2008). Audio interaction in computer mediated games. International Journal of Computer Games Technology, 1-8.

Pierce, J. S., \& Pausch, R. (2004,). Navigation with place representations and visible landmarks. In IEEE virtual reality (pp. 173-288). 
Rakkolainen, I., Raisamo, R., Turk, M., Höllerer, T., \& Palovuori, K. (2017). Extreme field-of-view for head-mounted displays. In 2017 3DTV conference: the true vision-capture, transmission and display of $3 D$ video (3DTV-CON) (pp. 1-4).

Reason, J. T., \& Brand, J. J. (1975). Motion sickness. Academic press.

Reason, J. T. (1978). Motion sickness adaptation: a neural mismatch model. Journal of the Royal Society of Medicine, 71(11), 819-829.

Rogers, S. (2019). 2019: The Year Virtual Reality Gets Real. Forbes. Retrieved June 20, 2020, from: https://www.forbes.com/sites/solrogers/2019/06/21/2019-the-year-virtual-reality-getsreal/\#52aaa2926ba9.

Salen, K., \& Zimmerman, E. (2004). Rules of play: game design fundamentals. Massachusetts, UK: The MIT Press.

Sherman, W. R., \& Craig, A. B. (2019). Understanding virtual reality: interface, application, and design. Cambridge, MA: Morgan Kaufmann Publishers.

Silverman, H. (2017). The Rule of 27s: A Comparative Analysis of 2D Screenspace and Virtual Reality Environment Design. In Totten, C. W. (Eds.), Level design: processes and experiences (pp. 309-322). Sound Parkway, NW: Taylor \& Francis Group.

Statista. (2020). Virtual Reality (VR) - Statistics \& Facts. Retrieved June 20, 2020, from: https://www.statista.com/topics/2532/virtual-reality-vr/.

Steinicke, F., Visell, Y., Campos, J., \& Lécuyer, A. (2013). Human walking in virtual environments. New York: Springer.

Virtual Reality Society. (2017). History of Virtual Reality. Retrieved from: https://www.vrs.org.uk/virtual-reality/history.html.

Woods, S. (2012). Eurogames: The design, culture and play of modern European board games. North Carolina, USA: McFarland \& Company Inc. 